\title{
Testicular Lipomatosis without Evidence of Cowden's Disease
}

\author{
Ahmad Rezayi Azandariani1, Leili Ebrahimi2, Sedigheh Saedi2\# \\ ${ }^{1}$ Department of Radiology, Faculty of Medicine, Hamadan University of Medical Sciences, Hamadan, Iran \\ ${ }^{2}$ Rajaie Cardiovascular Medical and Research Center, Iran University of Medical Sciences, Tehran, Iran \\ Email: lilieage@gmail.com
}

Received 20 June 2015; accepted 21 December 2015; published 24 December 2015

Copyright (C) 2015 by authors and Scientific Research Publishing Inc.

This work is licensed under the Creative Commons Attribution International License (CC BY).

http://creativecommons.org/licenses/by/4.0/

(c) (j) Open Access

\begin{abstract}
Background: Testicular lipomatosis is a very rare and benign disorder of the testicles. It usually presents as multiple bilateral ill-defined hyper-echoic intra-testicular lesions of different sizes but generally with maximum $4 \mathrm{~mm}$. Testicular lipomatosis is usually reported in association with Cowden's syndrome. Aim: We aimed to show that there are cases of testicular lipomatosis occurring in the absence of Cowden's syndrome. Case Presentation: We present a 28-year-old man with testicular pain, who was finally diagnosed as having isolated testicular lipomatosis without other clinical and biochemical abnormalities using magnetic resonance imaging (MRI) technique. Conclusion: We showed that the testicular lipomatosis may occur and be detected without any evidence of Cowden's disease.
\end{abstract}

\section{Keywords}

Testicular Lipomatosis, Cowden's Disease, Magnetic Resonance Imaging

\section{Introduction}

Fat tissue does not normally exist in non-neoplastic testis; however it may become detectable as a main feature of some subtypes of germ cells and stromal tumors [1]. Beside these tumors, collection of fat tissue in the testis can be found in those with the evidence of Cowden's syndrome or multiple hamartoma syndrome. Cowden's syndrome is an autosomally dominant inherited syndrome featuring multiple hamartomatous and neoplastic lesions in various organs and tissues including genitourinary tract but it could also be sporadic. It was first described in 1963 and the relevant gene is located on chromosome 10q23 encoding the phosphatase and tensin homolog

*General Cardiologist.

${ }^{*}$ Fellowship of Adult Congenital Heart Disease. 
(PTEN) gene [2] [3]. Fat containing lesions of the testis in Cowden's syndrome were initially described by Lindsay et al. [4]. Here, we describe a patient with testicular lipomatosis without evidence of Cowden's syndrome and show that this testicular lesion could appear independent of Cowden’s syndrome.

\section{Case Presentation}

A 43-year-old man presented with a recent history of testicular discomfort. Past medical history was negative for any specific illnesses or drug use. In family history, his younger brother had been previously diagnosed to have testicular lipomatosis. General physical examination showed no abnormality and the external genitalia and sexual development were normal. The patient underwent testicular ultrasound that revealed multiple hyper-echoic areas within the testis (Figure 1 \& Figure 2). In doppler ultrasound no evidence of increase vascularity was seen. Laboratory tests including follicle-stimulating hormone, luteinizing hormone, testosterone, prostate-specific antigen, and testicular tumor markers consisting of $\alpha$-fetoprotein, lactate dehydrogenase and beta- human chorionic gonadotrophin were performed and were reported to be within normal limits. Subsequently the patient was scheduled for testicular MRI for accurate diagnosis of the contour and extent of the masses and possible regional involvement. The imaging revealed that the testes were normal in size and contour, while multiple moderate to high intensity areas consistent with fat tissue accumulation were found in the testes (Figure 3 \& Figure 4). Using fat suppressed MRI sequences lesions lose their high signal intensity in favor of fat entity (Figure 5). There was no evidence of malignancy or extension beyond testes. Due to benign appearance of the lesions no biopsy was undertaken. The patient was advised to have regular clinic follow-ups and testicular self-examination to ensure there is no abnormal growth. As no other abnormalities, masses or neoplastic lesions were detected, the patient did not fulfill the criteria for the diagnosis of Cowden's syndrome.

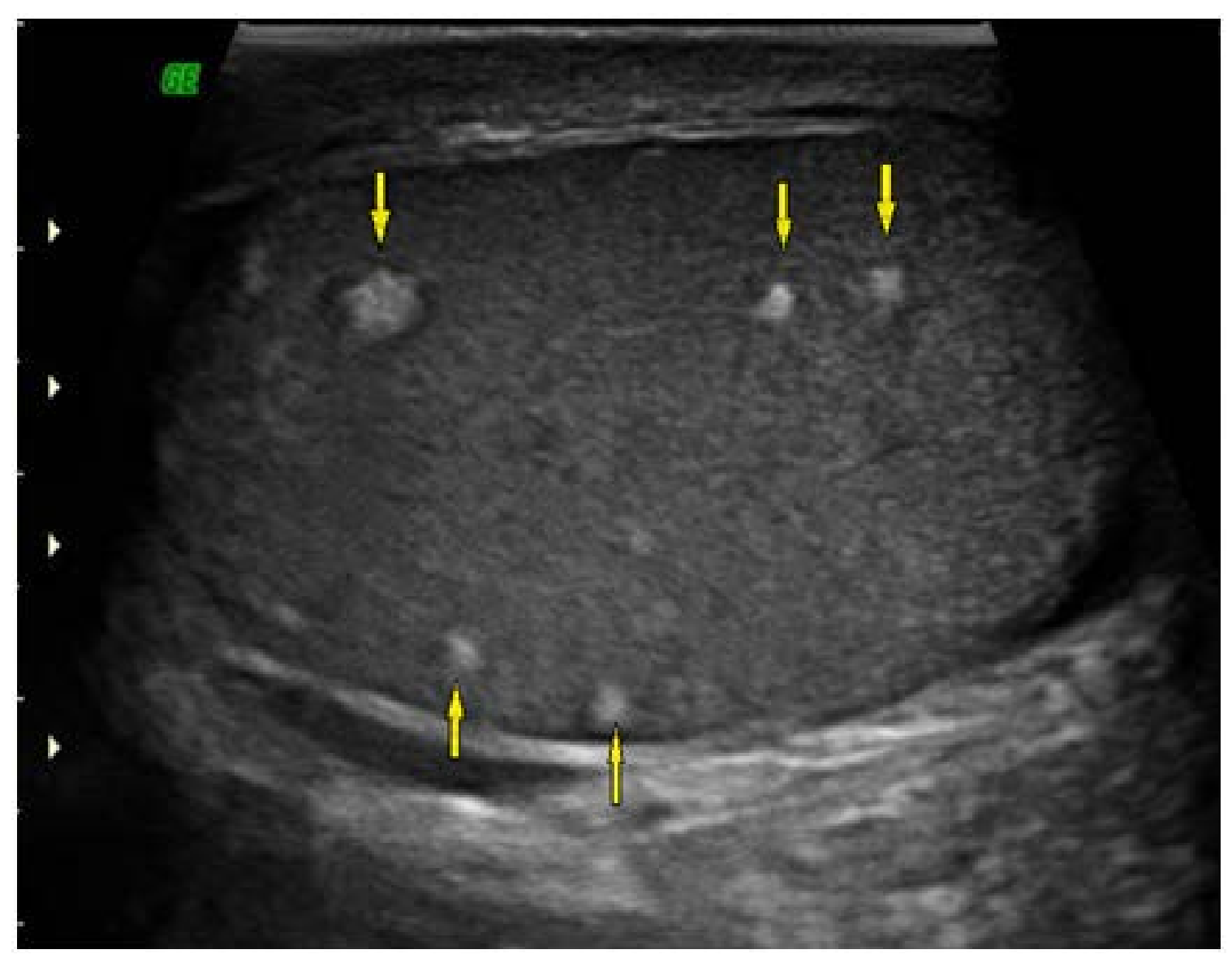

Figure 1. Ultrasound sagittal view demonstrate multiple ill-defined hyperechoic lesions with different sizes in testis parenchyma. 


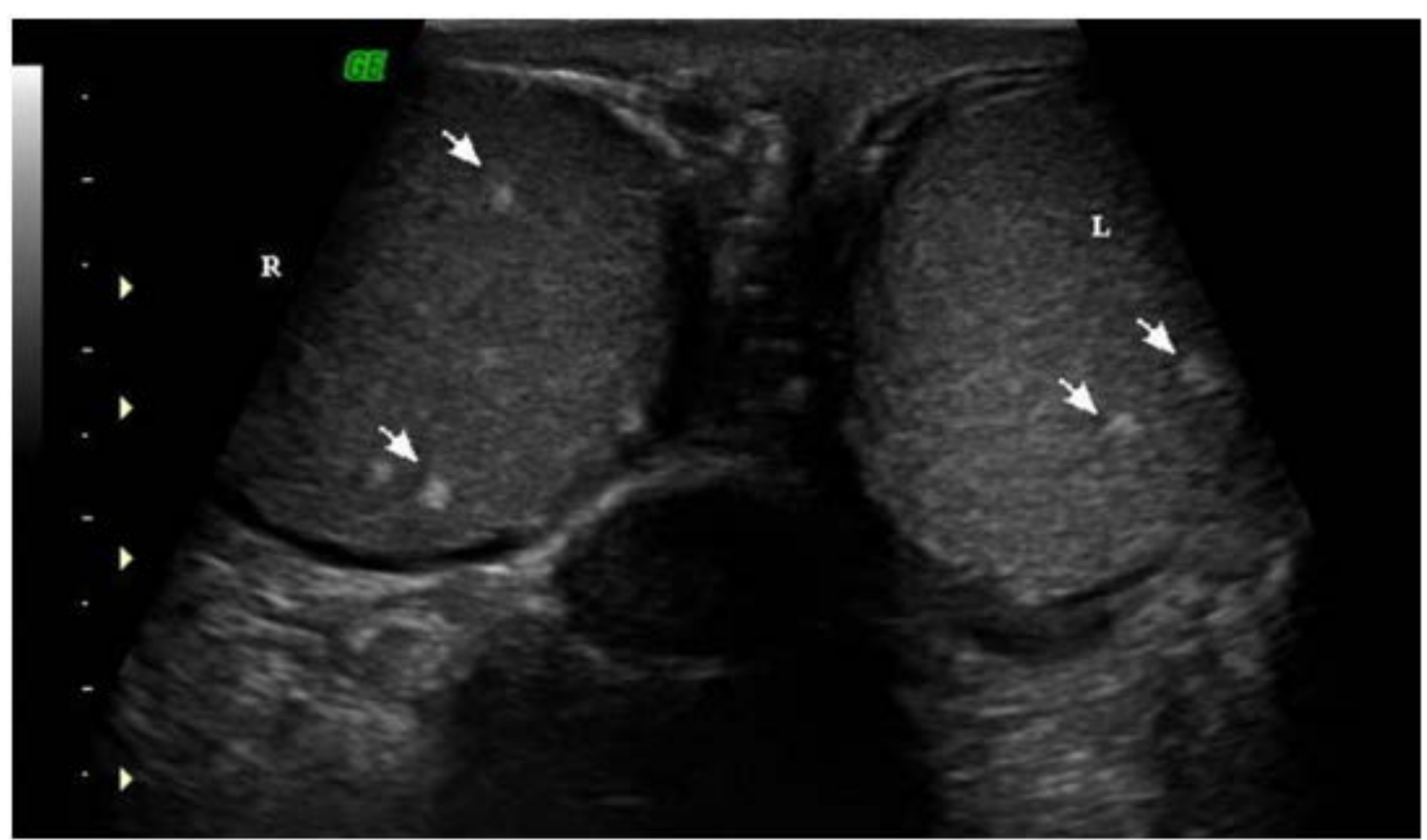

Figure 2. Coronal ultrasonic image of both testes show multiple bilateral ill-defined hyperechoic lesions in testis parenchyma.

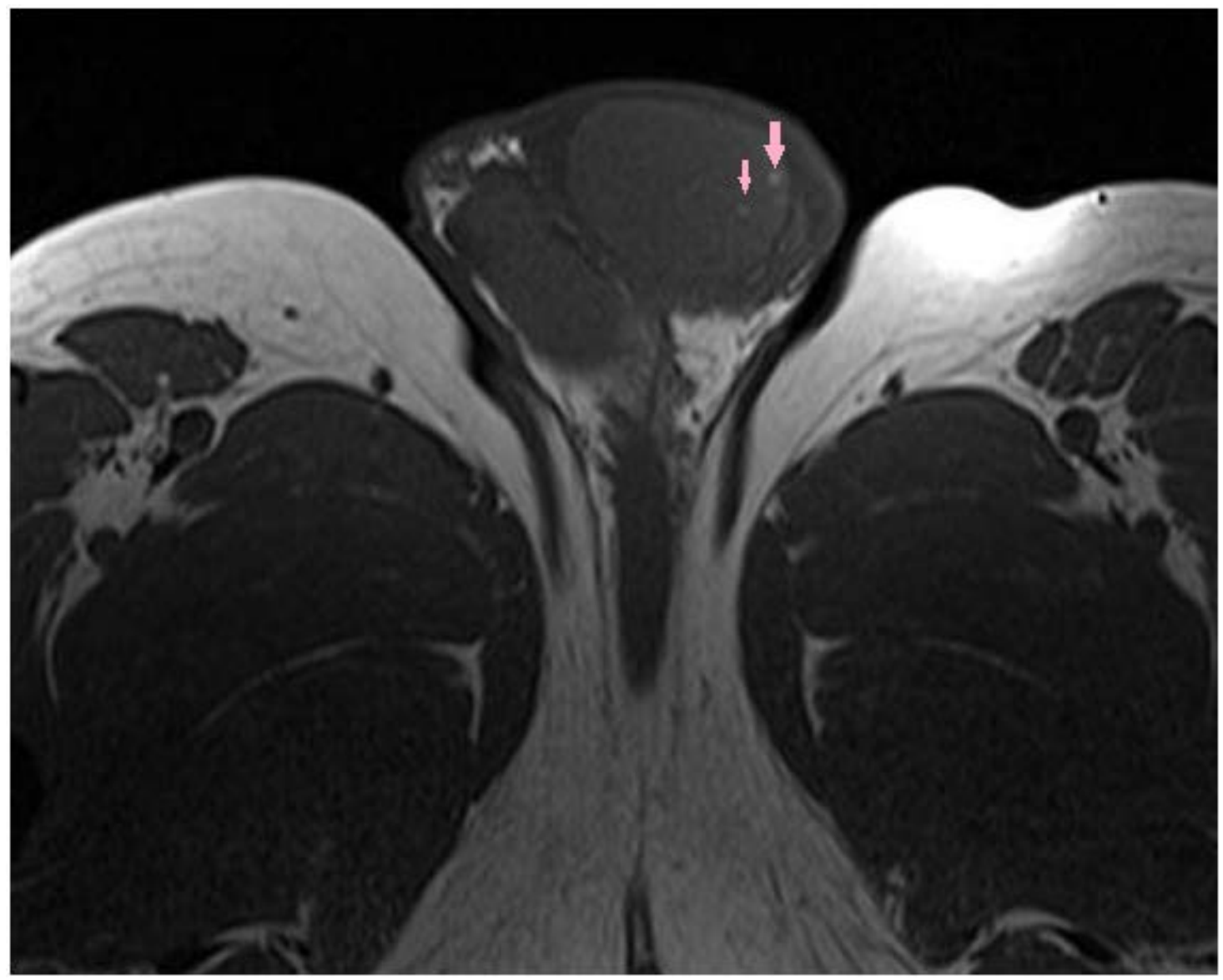

Figure 3. Axial T1W MR image shows multiple intermediate signal intensity lesions in testes (arrows). 


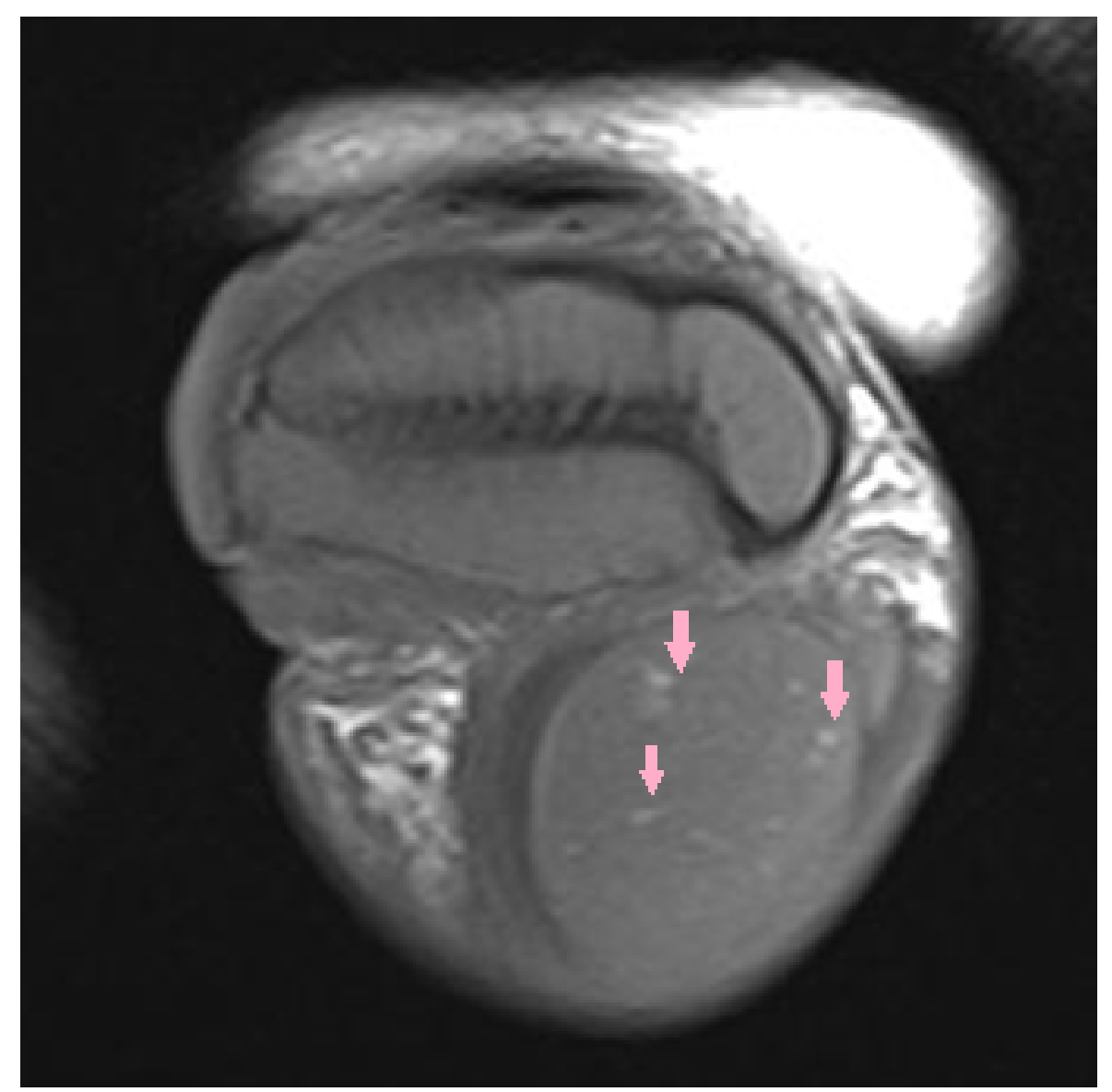

Figure 4. Sagittal T2W MR image shows multiple hyperintense testicular lesions (arrows).

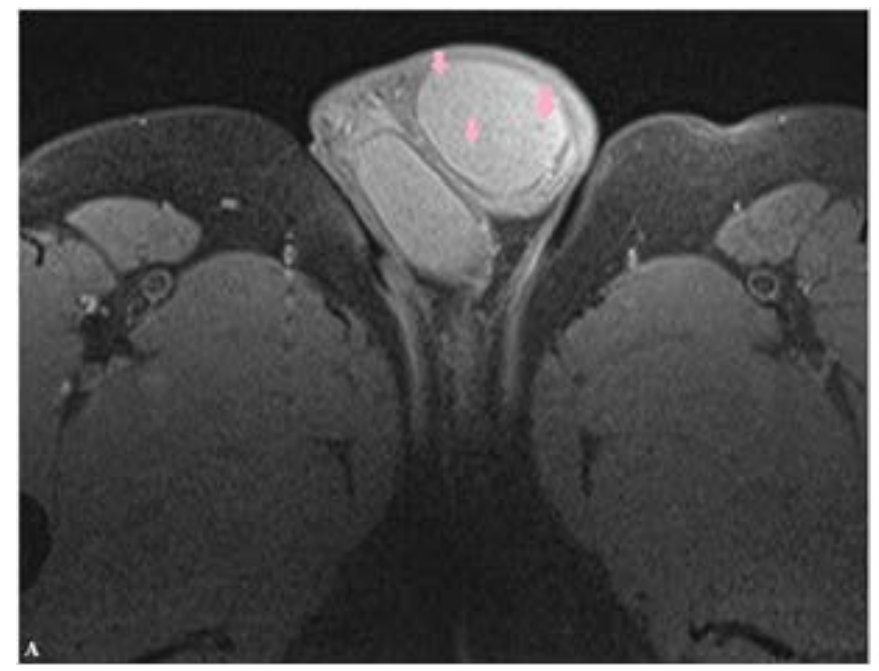

(a)

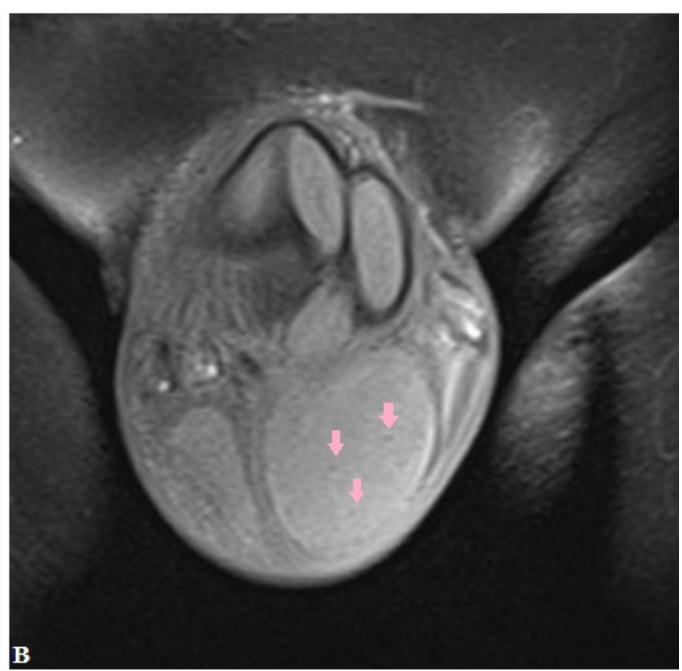

(b)

Figure 5. Axial (a) and coronal (b) FS T2W Images show lesions loss their signals after fat suppression favor for fat entity of lesions (arrows).

\section{Discussion}

Lipomas are common and benign type of soft tissue tumors and could be single or multiple. However accumulation 
of fat cells in the testis is not frequently reported other than in cases of tumors and neoplastic disorders or more often in the presence of genetic mutations like Cowden's syndrome [5]. The major criteria for diagnosing Cowden's disease include varieties of organic malignancies such as thyroid cancer, cerebellar tumors, endometrial cancer, breast cancer, and some other rare benign abnormalities such as multiple facial trichilemmomas, acral keratoses, and papillomatous papules that are usually present in more than $90 \%$ of patients [3] [5].

It has been demonstrated that adipocytes in testicular lipomatosis are usually derived from Leydig cell lines and high rates of fat accumulation have been shown in Leydig cell tumors. In fact, a morphologic change of Leydig cells to adipocytes has been shown by histological assessment. This histological change does not seem to affect spermatogenesis as was evidenced in our case [3]. The main massage of the current case presentation is that the testicular lipomatosis may rarely occur without any evidences of Cowden's disease or neoplasia. To the best of our knowledge this is a very rarely if not the first case reported with isolated testicular lipomatosis.

\section{Conclusion}

Our finding of collections of fat cells within the testis of patients without evidence of Cowden's syndrome or other abnormalities can be of interest and emphasize the fact that appearance of testicular lipomatosis may not be a specific phenomenon limited to those with Cowden's disease or genital tract tumors. In addition, the most important point is, that MRI specially fat suppressed sequences can help proving fat tissue in testicles and avoid invasive procedures such as biopsy.

\section{References}

[1] Ulbright, T.M., Srigley, J.R., Hatzianastassiou, D.K., et al. (2002) Leydig Cell Tumors of the Testis with Unusual Features. Adipose Differentiation, Calcification with Ossification, and Spindle-Shaped Tumor Cells. American Journal of Surgical Pathology, 26, 1424-1433. http://dx.doi.org/10.1097/00000478-200211000-00004

[2] Venkatanarasimha, N., Hilmy, S. and Freeman, S. (2011) Case 175: Testicular Lipomatosis in Cowden Disease. Radiology, 261, 654-658. http://dx.doi.org/10.1148/radiol.11091151

[3] Woodhouse, J.B., Delahunt, B., English, S.F., Fraser, H.H. and Ferguson, M.M. (2005) Testicular Lipomatosis in Cowden's Syndrome. Modern Pathology, 18, 1151-1156. http://dx.doi.org/10.1038/modpathol.3800448

[4] Lindsay, C., Boardman, L. and Farrell, M. (2003) Testicular Hamartomas in Cowden Disease. Journal of Clinical Ultrasound, 31, 481-483. http://dx.doi.org/10.1002/jcu.10209

[5] Woodhouse, J. and Ferguson, M.M. (2006) Multiple Hyperechoic Testicular Lesions Are a Common Finding on Ultrasound in Cowden Disease and Represent Lipomatosis of the Testis. The British Journal of Radiology, 79, 801-803. http://dx.doi.org/10.1259/bjr/50628431 